\title{
Comparative Study on Undergraduate in-class Teaching Quality Assessment at Universities in China and USA
}

\author{
Nongnong Shi, Yihua $\mathrm{Hu}$ \\ School of Life and Environmental Sciences, Hangzhou Normal University, Hangzhou, China
}

\begin{abstract}
This paper compares and characterizes various aspects of the undergraduate in-class teaching quality assessment systems at three universities in China and USA, including assessment objectives, recording methods, implementation, measures, result feedback and impact on instructors. The assessment systems have been evaluated for their characteristics, roles and problems. Recommendations and suggestions have been proposed to improve the assessment systems, including incorporating discipline-specific teaching quality measures, strengthening its role in teaching quality improvements, fixed value rating, and gradual addition of ability assessments. These recommendations and suggestions will provide useful guidance and implementable methods to effectively improve the teaching quality assessment systems for better teaching quality and outcomes.
\end{abstract}

\section{Introduction}

Classroom teaching is an important and basic form of education at universities. The quality of higher education is highly dependent on the quality of classroom teaching, which is directly related to quality of education, teaching and student training. Periodic assessments of the classroom teaching quality have been demonstrated to benefit the improvement of the education quality at universities. Therefore, scientific and efficient assessment systems would be important to gain comprehensive views of teaching quality and play important roles to improve classroom teaching quality [1]. In addition to peer-review, students as the major recipients of teaching and education should be the major evaluators in the assessment systems [2].

Hangzhou Normal University in China is in a process to optimize the undergraduate classroom teaching quality assessment systems. It is very important to timely take into considerations of similar evaluation systems at other universities, both domestic and international, to improve the system's scientific rationales, applicability and practicality. This would greatly enhance faculty's overall classroom teaching quality. We had a chance to participate and investigate the implementation of the undergraduate in-class teaching assessment systems at Indiana University Purdue University Fort Wayne (IPFW) and Kennesaw State University (KSU) in America. In the present paper, we would like to compare the various aspects of the assessment systems at IPFW, KSU and HNU, such as objectives, recording methods, implementation, measures, and result feedback as well as their impact on instructors. We also analyze the characteristics of the systems, their roles and weakness at the three universities in order to optimize our assessment systems to provide implementable strategies and methods for further improvement of the teaching quality at our university.

\section{Assessment objectives, recording methods and processes}

Teaching quality assessment is process where teaching is evaluated based on the teaching principles, laws and objectives, the using a set of practicable assessment techniques to dynamically reveal the relationship between teaching objectives and outcomes. The assessments are quantified in such a way that they could provide instructors with information and guidance for them to improve teaching practices to achieve the teaching goals [3].

\subsection{Objectives}

As brilliantly described by Stufflebeam, the objectives of the classroom teaching quality assessment are not to prove but to improve the teaching quality [4]. Therefore, the assessments typically consist of two components, one is to scientifically and unbiasedly assess the quality of teaching in classrooms, and the 
other is to provide information for improving the teaching quality. However, the objectives are different at different universities, as well as in different undergraduate teaching quality assessment systems. In this paper, we conduct a case study based on the assessment systems at IPFW, KSU and HNU.

The objectives of IPFW' and KSU's system are straightforward, targeting at individual teaching faculty to improve his/her teaching quality at classrooms. In contrast, the objectives of the assessments at HNU are multiple-layered, with some related to improve teaching quality and methods, and others used for instructor's performance evaluation and promotion, and still others used by functional departments for improving the university's teaching policy and schemes.

We agree that classroom assessments are not just for the assessment but to provide decision makers and education executives with unbiased information, and scientific options for setting up better teaching plans and their implementing strategies. This way, the assessments will help to improve teaching quality and promote education reform [5]. The multiple-layered assessments at HNU have been putting more pressure as well as motivation to teaching faculty as compared with IPFW's single objective system. The assessments have been demonstrated to effectively activate faculty members to proactively find their weakness in classroom teaching and ways to improve, including modifications of teaching methods and strategies, as well as optimization of teaching plans, thus leading to an overall elevation of the teaching quality at school level.

\subsection{Recording methods and procedures}

At IPFW and KSU, the assessments are mainly recorded on the tables printed on paper sheets by students at classrooms and delivered by designated staff to the school. At HNU, students use web-based teaching management systems to complete and submit their evaluations at planned time. They can log into the system with student's IDs and passwords to complete the assessments on-line. The internet-based assessment system offers several advantages over the paper sheet method used at IPFW, in terms of efficiency, easiness, convenience and privacy. It provides new channel for information collection, integration and analysis. The web-based system allows instant bottom-up flow of teaching quality evaluation information and top-down flow of new teaching guidance from the decision makers. It has greatly facilitated the processing of teaching quality information and helped the instructors to analyze their weakness, identify causes and find the solutions quickly and efficiently. This system has been demonstrated to be very useful in improving teaching quality, and exchanging know-how in teaching between universities [6].

\section{Implementation of the assessment}

The assessments at both universities have been made on semester basis. At IPFW and KSU, the assessments are conducted at department level, where students are asked to independently complete the questionnaires on paper, and the data are summarized and delivered to the deans or the supervisors of the faculty members being evaluated by teaching assistants (who are often graduate students or senior undergraduates). After the submission of student examination scores, the supervisors will provide assessment results directly to the faculty members, who are not allowed to involve any parts of the assessments in any way. At HNU, the assessments are organized by the School Academic Affairs Division, and students are asked to independently complete the assessments on-line by logging into the Division's assessment system website over a designated time period, which will then close after the deadline. The system will then analyze all the data collected automatically. A few weeks after the submission of student scores and completion of the assessments, instructors can log into the systems to view the evaluation results. The process prevents possible intervening from the instructors who are being assessed, to ensure the results are fair and objective.

The assessments at IPFW and KSU are conducted by individual departments in each college, while at HNU, they are organized solely by the School Academic Affairs Division. As such, the assessments at IPFW can be performed more flexibly and effectively in terms of timing and contents, to better meet the teaching goals in each department without interfering and disrupting daily activities. On the other hand, the simultaneous assessments across the departments organized by the School Academic Affairs Division at HNU allow exchange of better teaching experiences and know-how between the colleges in a timely manner, and would facilitate the planning of teaching and management programs for next stage at the school level.

\section{Measures for the assessments}

The assessments are aimed to be able to judge, examine, encourage and guide the teaching quality 
improvement. A scientific, effective and unbiased assessment system will help instructors to develop and improve their teaching idea, classroom behavior and overall effectiveness. It will also engage students to study proactively, scientifically and effectively, thus providing support for teaching and curriculum reforms as well as improving instructor's teaching skills. It is therefore important to develop a set of assessment standards to ensure that the assessments are performed precisely, effectively, scientifically and unbiasedly, and that the outcomes from the assessments can be used to achieve the objectives of the assessments, and used to play their roles in a positive way. The following six principles have been proposed to develop assessment standards that are rational, scientific and applicable [7]:

Integrative In the classroom teaching quality assessments, instructors are evaluated scientifically, systematically and comprehensively for their works in various aspects of classroom teaching activities. To achieve this, a complete set of indices and measures need to be prepared to represent the overall assessment goals with ability to differentiate individual indices and their relationships. These indices and measures need to cover all teaching processes, from course preparation to delivery, including conditional indices measuring teaching preparation, process indices determining the organization of teaching at classroom, teaching strategies, and use of teaching methods, and result indices indicating teaching outcomes and achievements.

Measurable All the indicators should be selected based on their quantifiability. In case where indicators are not quantifiable, they should be readily qualitative to give definitive conclusions. This requirement is proposed in accordance with the student's ability and characteristics, and would make the assessments easy to perform, efficient, reliable, accurate and unbiased [8].

Guidance The outputs from the assessment will provide the instructors with information that will evaluate their performance, assess their ability and encourage their improvements. The assessments should therefore be conducted to reflect the school's teaching ideas, education models and student training goals.

Objectiveness The assessment indices should reflect the characteristics of instructors and students the evaluators, and take into considerations of differences between disciplines, curricula as well as individual instructors. It is important to avoid using the same assessment criteria to evaluate instructors teaching in different disciplines or different types of courses.

Uniform and flexibility The assessment indices should be uniform to reflect the common teaching goals and requirements across the disciplines, and also be flexible to fit for disciplines based on their uniqueness and emphasis.

Simplicity Simplicity is important to ensure that the assessments can be conducted scientifically and easily with focused but few questions, and that data can be processed quantitatively and quickly.

At IPFW and KSU, the assessment system is highly flexible and objective without uniform assessment criteria across the school. The assessment criteriaare set up by the department itself to fully comply with the discipline's characteristics. The undergraduate courses compose of lecture courses and laboratory courses, each having separate assessment criteria.

\subsection{Appraisal for instructors in lecture course}

The assessment criteria at IPFW for lecture courses consist of two types of questions, one type is the multiple choices and the other is question and answer (Q-A). There are nine multiple choice questions, each having five choices for students to select based on their classroom experience to unbiasedly evaluate instructor's classroom teaching quality. Students can make selections based on their classroom observations and experience in the following multiple choice questions:

1) The instructor's concern about whether or not students learn the subject matter.

2) The instructor's ability to present the subject in an organized manner.

3) The instructor's ability to arouse my interest and stimulate my curiosity about the subject matter.

4) The instructor's ability to prepare exams which test for understanding as well as memorization.

5) The instructor's ability to explain complex material in an understandable manner.

6) The instructor's overall attitude toward students

7) The instructor's contribution to my gaining an understanding of the subject matter.

8) My overall evaluation of this instructor

9) (Optional) The grade I expect to receive from this course.

The students have five choices to answer the questions: excellent, good, fair, poor, very poor, each corresponding to a value of $5,4,3,2$, and 1 in data statistical analysis. For question 9, the choices are A, B, $\mathrm{C}, \mathrm{D}, \mathrm{E}$, and $\mathrm{F}$, with a value of $5,4,3,2$ and 1 , respectively.

There are five Q-A questions in the assessments without standard answers. Students are asked to answer these questions based on their classroom experience 
with the instructor to give a fair evaluation. These questions are:

1) What do you feel are the instructor's strong points?

2) In what ways might the instructor become a more effective teacher?

3) What do you feel are the positive points about this course?

4) In what ways might the course be improved?

5) Other comments related to the instructor, course, text, handout materials, knowledge gained, class schedule, etc..

The following evaluation measures are used at Kennesaw State University (KSU) to assess the instructor's in-class teaching quality for lecture courses:

1) If instructor provides clear description of curriculum requirements and regulations at the beginning of curriculum;

2) If instructor arranges the course to the syllabus;

3) If instructor starts the course according to schedule and make effective use of classroom time;

4) If instructor delivers the course contents clearly;

5) If instructor helps and mediates student discussions related to the course;

6) If instructor uses educational technologies to help improve student learning;

7) If instructor gives valuable feedback to student homework;

8) If instructor offers timely-feedback to students for their works at different time period;

9) If instructor is able to demonstrate the relevance of the course to the student's major;

10) If instructor is able to response to student's questions by e-mail, fax, telephone, or by changing working time during off-work time.

These ten points are scored by students as strongly agree, agree, fairly agree, disagree or strongly disagree on an evaluation questionnaire. At the same time, students can fill out a teaching suggestion form to answer two questions generally:
Firstly, which part of the course is most helpful to them (give examples of knowledge, exercise, and / or teaching management and methods), secondly, which part of the course need to be improved during the teaching process (if any). The KSU classroom teaching evaluation indicators are qualitative and basic, but they are closely related to the majors, particularly for the problems.

At HNU, the assessments are made in two parts, one is the teaching quality evaluation and the other is education reform-oriented evaluation, with a total score of 100 , where the former is $70 \%$ and the latter is $30 \%$. Each instructor's final score is calculated from all returned questionnaires after excluding $10 \%$ of the highest and lowest scores.

There are five questions in the teaching quality assessments:

1) My willingness to approach the instructor and engage in classroom activities.

2) The instructor answered my questions both in and outside the classrooms.

3) The instructor provided sufficient resources for me to study the courses.

4) The instructor encouraged me to raise questions and discover issues.

5) I learnt a lot after taking this course.

When summarizing the data, each of these questions has a maximal score of 10 (questions 1-4) and 30 (question 5), respectively, totaling 70.

Education reform-oriented evaluation has two questions:

1) Did the instructor dress up properly and behave well?

2) Did the instructor prepare the teaching adequately and deliver the teaching without reading from the textbook?

These questions have a score of 15 each, totaling 30 [9].

The new reformed teaching quality assessments for lecture courses is being established now. More specifically, they are toward teaching attitude, content, methods, ability and effects. In particular, these indicators assess:

1) if instructor delivers the course seriously and in an well-prepared manner;

2) if instructor starts and ends the class on time with fewer suspension and adjustment;

3 ) if instructor sets up higher standard of requirements, and is approachable, harmonious with students (teaching attitude); 
4) if instructor provides the course with abundant of contents and adequate resources for student self-learning;

5) if instructor is highly knowledgeable to talk about new achievement and progress in the majors (teaching content);

6) if instructor can use modern educational techniques or blackboard properly for the teaching content to help students to better understand the course content;

7) if instructor encourages student to ask questions and students are willing to participate in classroom activities (teaching methods);

8) if instructor provides clear and vivid teaching with clear emphasis of key and difficult points;

9) if instructor organizes the teaching smoothly with high quality teacher-student interaction (teaching ability);

10) if instructor inspires students to explore desire and motivates them to learn, resulting in an highly rewarding course;

11) if instructor pays attention equally to each student 's learning conditions, and is fair and just (teaching results);

12) Finally, students are invited to give suggestions for the instructor improve the teaching.

As you can see, the assessments at the three universities for lecture course are all developed in line with almost the six principles mentioned above, namely being integrative, objective and measurable. However, the assessments are not made and valued with the same questions at the three universities, with each having different emphasis based on its own education ideas, teaching models and student training goals.

In the IPFW's student assessment systems there are both qualitative-Q-A questions and quantitative questions-multiple-choice questions with equal values assigned to each question during statistical analysis. These questions are reflections of American college student's demands towards their instructors at higher level, where the appraisal is more focused on instructor's abilities, such their abilities to present the course in an organized way, to arouse student's interest and curiosity to the course, and to explain complex materials in an understandable manner and to prepare exams which test for understanding as well as memorization. Other important aspects in the IPFW's assessment systems are to evaluate instructor's commitments to the courses and concerns about the student's leaning in the course. The answers to the questions will help instructors have a better understanding of themselves and teaching results from the student perspectives. This would shape the directions of improvement for the instructors and their teaching. Obviously, the systems are measured at high level for classroom teaching quality assessments, and instructors will have to be highly committed, dedicated and diligent to obtain the ability rating required by the assessments. At KSU, the assessments are highly autonomous with close relevance to the majors.

In contrast to the IPFW's and KSU's systems, assessments at HNU are all quantitative in both teaching quality assessments and education reform-oriented evaluation, with different values assigned to different questions during the statistical analysis. $30 \%$ of the score is related to the knowledge acquisition of students, which is the largest proportion of all the assessments. The questions in the HNU assessments are written in a more friendly way in an attempt to reflect the student led classroom teaching model, where instructors are playing a role as guide, narrowing the distance between instructors and students. But the downsides in the assessments is that there is no question to evaluate instructor's ability, and no must to answer questions. Answers from these questions could provide a better way for instructors to understand themselves, because these answers reflect the student impression about the instructors, particularly about their weakness that needs to be addressed. However, there are certain innovations in the HNU assessments, including question that evaluates instructor's grooming and appearance in classroom with $15 \%$ of the total score, higher than or equal to other measurements except the one measuring student knowledge acquisition, reflecting the new era of style requirements for university instructors.

After comparison and analysis of the student in-class assessments for lectures at two US and one Chinese Universities, we have identified strength and features for each of them.

\subsection{Appraisal for instructors in laboratory course}

The assessments for laboratory courses in IPFW have multiple-choice questions and Q-A questions as well. The former has nine questions, each with five choices. Students are asked to answer these questions based on their classroom participation and experience:

1) The instructor's concern about whether or not students learn the subject matter.

2) The instructor's ability to conduct the laboratory in an organized manner. 
3) The instructor's ability to arouse my interest and stimulate my curiosity about the subject matter.

4) The instructor's assistance in lab.

5) The instructor's ability to explain lab exercises in an understandable manner.

6) The instructor's overall attitude toward students.

7) The instructor's contribution to my gaining an understanding of the subject matter

8) My overall evaluation of this instructor score.

9) (Optional) The grade I expect to receive from this course.

The answers to these questions have five choices: excellent, good, fair, poor, very poor, each corresponding to a value of $5,4,3,2$, and 1 in data statistical analysis. For question 9 , the choices are A, B, $\mathrm{C}, \mathrm{D}, \mathrm{E}$, and $\mathrm{F}$, with a value of $5,4,3,2$ and 1 , respectively.

There are five questions to answers in Q-A section in the assessments, without standard answers. Students are asked to answer these questions based on their classroom experience with the instructor. These questions are:

1) What do you feel are the lab instructor's strong points?

2) In what ways might the lab instructor become a more effective teacher?

3) What do you feel are the positive points about the laboratory portion of this course?

4) In what ways might the laboratory portion of this course be improved?

5) Other comments related to the instructor, laboratory, lab manual, handout materials, knowledge gained, class schedule, etc..

At $\mathrm{HNU}$, the teaching quality assessments for laboratory courses are also consist of two parts as for the lecture courses with a total score of 100 , among them $70 \%$ are for teaching quality evaluation and $30 \%$ for teaching reform-oriented evaluation. The final scores of the instructors are calculated as described above for the lecture courses.

Teaching quality assessments are made with the following five questions:

1) I was willing to approach the instructor and participated in the class activities.

2) The instructor showed me correct and standard laboratory procedures.

3) The instructor played attention to improve my laboratory skills and asked me to write experimental reports.
4) The instructor provided timely laboratory instructions and assistance.

5) I feel rewarded through participating in the laboratory courses.

Full scores are 10, for questions 1 to 4 , and 30 for question 5, totaling 70 .

The teaching reform-oriented evaluation has two questions:

1) Did the instructor dress up properly and behave well?

2) Did the instructor supervise you in designing experiments independently and encourage you to do exploratory experiments?

Each of the questions is assigned a value of 15, totaling 30[10].

The new reformed teaching quality assessments for laboratory courses are also established recently in HNU. More specifically, they also consist of 5 aspects stated above. In particular, these indicators assess:

1) if instructor delivers the course seriously, well-prepared and reviews the laboratory reports carefully;

2) if instructor sets up higher standard of requirements, and is approachable, harmonious with students (teaching attitude);

3) if instructor provides the course with abundant and updated contents, and encourage students to carry out exploratory experiments, or prepares experiment method with students (teaching content);

4) if instructor pays attention to all students during the laboratory courses and provides on-site instruction and correct student mistakes;

5) if instructor encourage students to ask questions and evaluate based on experiment results, introduction report and operational skills ( teaching methods);

6) If instructor teaches clearly with clear emphasis of key and difficult points; if instructor is able to point out the experiment precautions;

7) if instructor is familiar with experimental design, and has excellent experimental skills to demonstrate (teaching ability);

8) if instructor inspires students to explore desire and motivates them to learn, resulting in 
continuous improvement of laboratory skills and ability to practice (teaching results).

9) Finally, students are invited to give suggestions for the instructor to improve the teaching.

Obviously, the assessments at the two universities for the laboratory courses are all developed also in line with six principles mentioned above, namely being integrative, objective and measurable. However, the assessments are not made and valued with the same questions at the two universities, with each having different emphasis based on its own education ideas, teaching models and student training goals.

At IPFW, the student assessment measures for the lecture and laboratory courses are similar, both having qualitative and quantitative questions, with equal values assigned to each question during statistical analysis. The measures are focused on instructor's laboratory knowledge and skills, as well as their commitment to the laboratory course and attentions for students.

In comparison with IPFW's assessment system, the measures for the laboratory courses at HNU are similar to those of the lecture courses, where all measures for teaching quality evaluation and teaching reform-oriented evaluation are quantitative with different values assigned to different questions during statistical analysis. Assessments for the laboratory courses highlight the student-led inquiry study process with instructor's functioning as guide. Therefore measurements on the knowledge gain by students are the priorities with $30 \%$ of total score, the largest among all the measurements. This assessment system is fully in line with the characteristics of the laboratory courses, such as independent design, exploratory experiment, and imposes higher demands on instructors for their organization and implementing ability.

\section{Feedback and impact on instructors}

At IPFW, the assessment results are directly provided to the instructors by the deans after students complete the assessments. The instructors have options to use the information or suggestions to modify, adjust or continue their teaching methods, according to their own situations. Timely feedback of the assessment results would therefore have positive impact on instructor's efforts to improve teaching quality and teaching results.

During the annual teaching review, IPFW faculty members will discuss with their managers about how to overcome their deficiencies in teaching, and how to improve classroom teaching quality and attractions to students for better teaching results. These discussions will take into considerations of the assessments, as well as other feedbacks and suggestions from students, and will exchange experience and knowledge with other faculty members. There might be some disagreements between students and instructors regarding certain teaching methods. For examples, students may not prefer to have group discussions on some topics, or group experiments, while experienced instructors believe these are useful in inquiring study models. In such case, instructors could elect to continue their classroom teaching models and methods.

Generally speaking, the feedbacks and suggestions from most of students during the assessments are quite professional and helpful for improving classroom teaching. However, a few students may make complaints and express discontents during the assessments. If these complaints are repeatedly made against an instructor, the instructor's promotion and salary raise would be negatively affected. In such case, school will provide help and suggestions to the instructor in a case by case manner. If the instructor is repeatedly getting negative feedbacks over several assessments with a lot of complaints, the dean will have a personal meeting with him to address the issues and discuss the ways to improve. If no significant improvement is made after that, the instructor may risk to be discontinued or replaced from the teaching position. As such, the assessments have been used as a tool to implements the idea of to 'improve' the teaching results. Instructors typically welcome and hope to see the true feedbacks and evaluations from students for their teaching efforts because these feedbacks can help to improve the teaching quality and teaching works, as well as instructor's ability and competences.

Each year, supervisors at KSU meet during their annual teaching review to discuss ways to improve teaching, taking into consideration of the teaching assessments, suggestions and options from students. Some students may dislike some kinds of teaching methods, such as group discussion, which most instructors believe they are very effective. These methods will be continued. In general, feedbacks and suggestions from students are very professional and constructive, and are very helpful for teaching improvement. Very few students make complain or grouch. If an instructor is complained by many students, it will have negatively impact on the promotion and rise for the instructor. If that happens, KSU will provide assistance and advice to the instructor. 
At HNU, after the completion of the assessments, instructors can view the results of the assessments by logging into the system's website, where the scores for every question are displayed in detail. However, the measures used in HNU's assessments are mostly quantitative with few suggestions and comments from students, who make scores instead of making comments or suggestions for most of the questions during the assessments. This is not useful for the instructors to get detailed options and suggestions from students to improve their teaching in more precise and specific ways. After summarizing the assessments, the results are rated as $\mathrm{A}, \mathrm{B}$ and $\mathrm{C}$ in each college based on the percentages allocated by the school, where the $10 \%$ of instructors at low end of the scores are rated as $\mathrm{C}$. However, there are often situations where the scores between the rates are very close, with differences of less the 0.1 points. Therefore, such rating may be unfair to the instructors at the dividing lines between the ratings, and could have negative impact on these instructor's teaching initiatives [11].

\section{Conclusions}

In this paper, we have described and discussed various aspects of classroom teaching quality assessment systems, such as objectives, data recording, implementation, evaluation measures, result feedback, and their impact on instructors. We compared the assessment systems at IPFW, KSU and HNU, and have identified a few distinct aspects or bright spots in each assessment system.

The assessments at IPFW are more focused on assessing instructor's ability for a numbers of teaching activities, and their commitments to the classroom teaching. At KSU, the assessments are highly autonomous with close relevance to the majors. At HNU, the emphasis is to evaluate if the instructor's classroom teaching is to promote and reflect the education idea of student-led inquiry teaching. These differences on the assessments represent the differences in their unique education ideas, teaching models and training goals between the two universities.

To further improve the assessment systems and make them more comprehensive, scientific and practicable to play better and more important roles in improving teaching quality and results, as well as to protecting instructor's efforts on these areas, we would like to propose the following recommendations: 1) while keeping the key elements in the advanced and proven systems, assessment measures should be modified to be more discipline-specific and -oriented, and these measures and detailed questions should determined by relevant functional divisions at college level, so that assessments can be made more suitable and relevant to the discipline's characteristic's and requirements. 2) Put more emphasis on the assessment that addresses the objectives to improve classroom teaching quality, and make the rating more scientific and rational to protect instructor's teaching enthusiasm and push more instructors toward highly rated groups. We would like to suggest a fixed value rating system to rate the instructors. 3) Gradual addition of measures that are reflective of instructor's various abilities to make the assessments being conducted at higher level with higher and comprehensive targets. This would eventually help to enrich and improve our teaching quality assessment systems.

Finally, We are pleased to tell that the reformed value rating system at $\mathrm{HNU}$ will be operated more humanistic and rational. The scores will be in three levels (excellent, good and unmet expectation). Instructor with score of the lowest $10 \%$ in each college will be reviewed by expert panels appointed by college to identify issues and provided assistance to improve their teaching quality.

\section{Acknowledgements}

We would like to show our hearty thanks to the academic affairs in IPFW, KSU and HNU for their kindly offering the in-class teaching quality assessment criteria individually. This paper was supported by the programs 'Bilingual Superior Course for Genetics in Hangzhou' funded by Hangzhou Bureau of Education (2014), 'Bilingual Teaching Training in IPFW' (2012) and 'Advanced Teaching Training in KSU' (2011) by Hangzhou Normal University.

\section{References}

[1] Wang, L. (1995): Educational evaluation study, Henan University Press, Henan China.

[2] Zhang, J., Wang, J. and Xu, W. (2002) 'Teaching Quality Evaluation: Problems and Solutions', Journal of Anhui Teacher's College 26 (3), pp. 79-81.

[3] Zhang, W. (2007) 'Comparison of teaching evaluation systems for American and Chinese universities', Theoretical Observation 4, pp. 189-190.

[4] Chen, Y. (1998): Educational evaluation study, People's Education Press, Beijing, China. 
[5] Wu, G. and Zhang, H. (2001) 'Classroom teaching evaluation in University', Jiangsu Higher Education Research 6, pp. 62-64.

[6] Zhao, J., Yang, Y. and Cui, Y. (2008) 'Study on improvement of undergraduate teaching evaluation', Journal of Xi'an University of Arts and Science (Social Science Edition) 11 (4), pp. 68-70.

[7] Chen, M. (2010) 'Construction of university teaching evaluation index system', Journal of Nanjing Institute of Technology (Social Science Edition) 10 (3), pp. 50-53.

[8] Lin, Z. (1992): Psychology for University Student, Fujian Education Press, Fuzhou, China.

[9] Academic Affairs. 'In-class teaching quality evaluation form - Academic Management System for Hangzhou Normal University (for the lecture courses)', http://jwc.hznu.edu.cn/zfweb/index.htm (April 2013).

[10] Academic Affairs. 'In-class teaching quality evaluation form - Academic Management System for Hangzhou Normal University (for the laboratory courses)', http://jwc.hznu.edu.cn/zfweb/index.htm (April 2013).

[11] Mckeachie, W. J. (1997) 'Student ratings: the validity of use', American Psychologist 52(11),

pp. 1218-1225. 